\title{
(i)
}

This work is licensed under a Creative Commons Attribution 4.0 International License

https://creativecommons.org/licenses/by/4.0/

https://doi.org/10.24833/2687-0126-2021-3-4-33-50

\section{TRANSLANGUAGING KNOWLEDGE REMOTELY: THE ANALYSIS OF AN ACADEMIC WEBINAR}

\author{
Mohammed Nasser Abdulsada \\ Wasit University (Iraq) \\ malsharhani@uowasit.edu.iq
}

\begin{abstract}
This paper explores how academic webinars are translanguaged by drawing on the sort of linguistic strategies and techniques implicated in these webinars. The research, therefore, poses two key questions relevant to how knowledge is communicated and what strategies are used in this communication. The main hypothesis of the research maintains that academic webinars communicate knowledge from a single professional presenter to many knowledge-receiving attendees, based on a presupposed view that presenters and moderators in webinars adhere to certain linguistic and conversational moves. To explore how academic webinars proceed and what they imply, a single academic webinar is randomly sampled for analysis. First, academic webinars are analyzed, key terms defined, and some previous literature on the topic overviewed. Then, the sampled webinar is administered for analysis (gathering, transcription, analysis), and a discourse-conversational model of analysis is applied. The author concludes that webinars are knowledge-specific and highly professional in their character, and they manifest certain linguistic and discourse strategies. The research also reveals that webinars feature such strategies as reformulation, mono-versation, on-screen sharing, speaker invisibility, indirect engagement, inactive moderation, and graphic interaction. Further recommendations suggest a more linguistic investigation into online learning, whether in webinars, online workshops, massive open online courses, or in any virtual learning practices.

Keywords: webinars; academic discourse; digital discourse; online learning; digital conversational analysis; translanguaging; computer-mediated discourse.

How to cite this article: Abdulsada M.N. (2021). Translanguaging Knowledge Remotely: the Analysis of an Academic Webinar. Professional Discourse \& Communication, 3(4), pp. 33-50. https://doi.org/10.24833/2687-0126-2021-3-4-33-50
\end{abstract}

\section{Webinar}

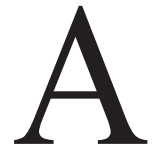

webinar is an online, live presentation or discussion in which presenters deliver a certain topic or theme, and viewers can submit questions, interact and participate in discussions. The word "webinar" is a neologism created by blending parts of the words web+seminar. Merriam-Webster online dictionary [2021] defines webinar as "a live online edu- 
cational presentation during which participating viewers can submit questions and comments." In webinars, various themes and topics can be presented; business, education, technology, etc. Webinar presenters choose topics that are familiar but very focused on detail, hence new, rather than familiar and known, themes are expected to be discussed in webinars.

An academic webinar is an online knowledge-specific mini-session, delivered to address a certain academic area. Though there are nowadays various online forms of presentations and discussions, e.g. workshops, courses, meetings, conferences, and, with different themes; academia, business, development, yet webinars are still the generic umbrella term for any online theme-oriented presentation.

Clay [2012, p.20] defined webinar as "an interactive, scheduled, e-learning experience that occurs in real-time with an instructor or a facilitator as a web workshop." Zoumenou et al. [2015, p. 62] and Mohorovicic et al. [2011, p. 1271] agree that webinar is "a presentation, seminar, lecture, or workshop transmitted over the internet, includes video, audio and textual communication between participants."

Webinars, particularly academic webinars, were chosen as the object of this study because they involve various themes and topics, and they feature different linguistic and non-linguistic structures and devices. Unlike other online presentations, such as courses, webinars are multi-purpose and multi-thematic, and they also manifest various strategies of communication and interaction.

This paper investigates academic webinars by drawing on the digitalization of knowledge communication as a means of linguistic interaction. Moreover, this research draws on interaction and the communication of knowledge as key elements in academic webinars.

\section{Online Communities, Practices, and Discourses}

Online learning stands for virtual discussions, debates, workshops, classes, courses, meetings, and trainings, which are streamed online or on the Internet in real-time, live, synchronous, recorded, or asynchronous settings. All these practices represent the online environments of learning where knowledge is exchanged or presented. The active participants in these environments are presenters, moderators, and listeners, as well as end-users. These environments operate in interaction-based and learning-driven practices. When presenters deliver an online course or training, they in fact interact with other participants; moderators and listeners. Their interaction is embodied in various strategies and practices that embrace the language, discourse, conversation, communication.

Let us dwell on the idea of a webinar itself and its manifestation in the academic environment by analyzing some issue-related literature. Gee \& Green [1998] in their works attributed considerable importance to knowledge in learning settings and discourses, where they discussed the construction of knowledge in classrooms and other educational fields. They found that knowledge proceeds according to time, events, and groups. Gee \& Green also held that the discursive construction of learning and knowledge has to do with the social practice of members. The research highlighted the social aspect of knowledge as a mobile factor that has time to take place.

Fetisova et al. [2018] maintained that "One of the most effective and relevant forms of modern interactive teaching a foreign language in non-linguistic universities implementing a competence approach is a webinar." [Fetisova, 2018, p.6].

In terms of teaching and learning, as well as professional training in general, webinars are considered under a bigger and more generic umbrella term, that is information and communication technology (ICT), an online community of learning (OCL), and Computer-supported collaborative 
learning (CSCL). ICT is about the use of technology-based practices of teaching and learning, including TV, Internet, radio stations, visual presentations, etc. CSCL is the adoption of mass and group methods of online learning and teaching through streaming computers or mobile devices. OCL is the overall presence of learners, teachers, professionals, tutors, and trainers and their participation in virtual, online classes. It is a virtual academic setting of online learning-driven interaction involving participants, including the presenter or of the topic.

Mohorovicic et al. [2011] posited that webinars can be used in various fields such as the business sector for employee training, meetings, teamwork, and product and services presentations. In the field of education, webinars are collaborative tools that enable interaction between students and teachers with the help of polling, question and answer sessions and whiteboard, and can be used for blended environments.

Newman [2013, p. 8] held that "Webinar technology is rapidly growing in both usage and capability. One of the areas experiencing such rapid growth involves education and training. Largely because of significant savings in time and money, companies are increasingly turning to online technology for education, product demonstrations, and training." Newman added that "webinars save money and time, and teacher has complete freedom to choose a comfortable place and environment to join a webinar."

Reneland-Forsman \& Magnusson [2019] evaluated academic thinking in Norwegian, Finnish, and Swedish teaching webinars. They conducted webinars where students are in direct online communication with researchers to support participants' skills. The experiment provided an opportunity to identify different skills, such as socialization, scholarly engagement, and knowledge acquisition. They remarked that "A carefully staged webinar using these two critical aspects, offers socialization of students in professional training, to an academic discourse where the production and evaluation of knowledge is part of students' identity and constantly debated." [Reneland-Forsman \& Magnusson, 2019, p.6).

Drabkina \& Tanchuk [2020] posited that "webinar combines not only educational and Internet discourses linguistic characteristics, but also features of written and oral types of communication, it is crucial to study how discourse markers organizing the information in a webinar can be presented and interpreted." [Drabkina \& Tanchuk, 2020, p.105].

\section{Related Literature}

Investigating webinars, along with the relevant linguistic and non-linguistic areas, has been a prominently dynamic theme, especially in learning and teaching areas. Doherty-Sneedon et al. [1997] compared face-to-face communication to online, mainly video-mediated, communication in linguistics and other aspects. The authors held that participants' ability to physically interact in both mediums differs considerably with the presence of dialogue as linguistic communication. The participants in video communication tend to elicit feedback and to concentrate on visual effects, while the participants in face-to-face communication focus on conversation, direct interaction, and turn-taking. It seems that remoteness vs. 'face-to-faceness' plays a remarkably important role in determining how conversations proceed and how participants co-operate.

Tan \& Tan [2006] followed a conversational approach to compare face-to-face and online conversations taking place in learning settings, in particular those between learners and instructors. They concluded that real interactions offer more strict norms of conversational statuses as constructed in turn-taking, interruption, and others, while online interactions are less governed by conversational norms, given the uniqueness of these interactions. They also indicated that online 
environments of learning are unpredictable as to discuss roles and assignments when it comes to instructor-student interactions, unlike in-person or physical environments where roles are defined and tasks are assigned.

In the works of Ho \& Swan [2007] we may find deep analysis of online learning through a conversational approach carried out by evaluating the principles of conversational analysis in online environments of learning. The authors state that the socio-cognitive process of learning in online settings helps explain the developmental performance of learners in these settings; the learners in these settings depend on conversation turns to enhance their asynchronous interactions. It is important, therefore, that emphasis is put on online learning settings to reveal the linguistic implications that are worth analysing, especially, those related to participants' roles and acts in such settings.

The use of webinar tools in the online learning practices of trainers and students was questioned in the study done by Wang \& Hsu [2008]. Their study contained several implications relevant for online learning that can support and advance e-learning practices through the webinar tool Elluminate. The authors indicated that the application of real-time webinar-based learning practices requires the understanding of interactive learning environments surrounding such practices. One of the key elements required in e-learning application practices is the facilitated distribution of information to knowledge seekers represented by trainees and students.

Stein et al. [2010] studied the impact of webinars on medical students in Japan through the observation of clinical online sessions and whether these sessions were effective in students' learning. The researchers conducted real-time online seminars on medical applications and examined how students respond and interact with tutors. They reported that online seminars are feasible with and without tutors, students showed interest and enthusiasm for these practices and expressed a desire for more skill development courses.

A study by Hoeldtke \& Raake [2011] on interactivity in multiparty conferencing attempted a quality analysis of conversations in online exchanges. They conducted a practical experiment by applying conversational and statistical measures. They designed turn-taking scenarios and situations. Hoeldtke \& Raake [2011] argued that there are several factors affecting multi-party conversations, including naturalness, topic relevancy, and multi-talk interruptions.

Agnes [2012] focused on the link between participation and engagement in student-oriented webinars with behavior as a pivotal element in online communication. He questioned this through the way participation in webinars can predict students' behaviour and engagement in online learning, and the sort of students' experiences and perspectives revealed in webinars. He found that students' perceptions of online engagement are still limited and unpredictable considering the flexibility of the existing models and techniques of online learning and teaching.

Sutton [2012] showcased the impact of online university courses on students' interaction and discourse, especially in relation to critical thinking and verbal participation. By examining the interaction of students registered in online graduate courses, Sutton found that instructors, assignments, and techniques have all affected students' construction of knowledge and enabled them to create meaningful discussions, and therefore they helped facilitate knowledge distribution.

A large number of theoretical sources are devoted to the educational use of webinars with different foci on technologies, teachers and students, academic environment in general.

Let us start with the research by Başaran [2014] who studied the use of webinars as educational technology in teaching by examining the challenges, benefits, and potentials of these techniques in language learning and teaching. The author stated that the key challenges to webinars are technical and logistic difficulties and aspects, as these are held remotely with no control on attend- 
ance, even though there are various advantages of webinars in ELT (English language teaching) settings.

Another author who studied webinars in terms of academic value - Mihai [2014] - focused on the teachers involved in webinar presentations to gain insights on how teaching is formulated in e-learning settings. By shedding light on e-learning webinars as an end and a tool for knowledge dissemination in selected teachers' courses, Mihai found that synchronous and asynchronous online webinars can achieve teaching goals, which is possible through more research in online pedagogical practices.

Wen et al. [2014] measured students' engagement in massive open online courses, known as MOOCs, by adopting online course posts as analyzers of motivation and dispreference. Online communities of learning were shown to have provided insights into the way participants engage, participate, share, and reflect. Wen et al., additionally, identified certain manifestations of support in online courses that are useful in justifying students' behavioural strategies while engaged in an online course.

Learning environments are a subject matter of Moore's research. Moore et al. [2016] questioned the importance of engagement in online learning environments, especially those involving teachers and learners. The researchers evaluated responses based on participants' feedback, reaction, and attitude. Moore et al. concluded that discourse plays a significant role in the creation of virtual learning sessions, and they argued that development is necessary for enhancing online environments of learning. While online environments of learning tend to be socially orientated, social factors impact a professional development of teachers as they need to be attentive to many details encompassing learning and teaching.

Ruiz-Madrid \& Fortanet-Gómez [2017] maintained that webinars implicate a digital genre of interaction that is intended for knowledge and collaboration due to such other irrelevant factors as internationalization of teaching and learning, advancement of academic skills, and the emergence of communication technology. They found that participants in webinars adhere to communication as an invisible technique where presenters and audiences use a handful of strategies, including screen sharing, paralanguage, kinesics, and interaction. The researchers also admitted that further research is needed to realize the generic characteristics of any online genre.

Fetisova et al. [2018] measured the efficiency of webinars in enhancing the mastery of foreign language skills on the ground that webinars are interactive learning tools. The researchers concluded that "Ongoing reforms of higher education and the requirements of information and communication technologies contribute to the development and implementation of new effective methods and forms of interaction in education, making qualitative changes in the teacher-student relationship. Such changes are possible mainly due to the interactive means of learning with the use of distance learning technologies" [Fetisova et al., 2018, p. 6].

King [2018] examined the role of webinar moderators in the creation of interaction where they ensure a smooth procession of conversation among participants. Question-answer sequences are the most common aspect of conversational interaction in webinars and the moderators' role is to select respondents. According to King, there are pre- and post-question selections in webinars, and this can affect how moderators and audience interact.

Stoytcheva [2018] concluded that online learning practices, especially in a collaborative style, construct knowledge at individual and group levels, where opinions and discussions are allowed to build communication and to enhance interaction. This, accordingly, will help to make professionals and experts realize educational goals and objectives by drawing on current practices of online 
collaboration. Stoytcheva also found that linguistic and professional competencies are important in the designing of learning skills.

Warren [2018] based his study on the conversational analysis approach to find the discourse strategies worth analyzing in such online exchanges. He found that interaction in online discussions follows a question-answer routine where teachers and students build an online setting of feedbacks and responses and thus boost conversational interaction. His analysis suggested that online teacher-student discussions are assigned to roles or participant frameworks and various strict conversational norms, and that students valued teacher-provided interaction because it allowed more communication for the sake of knowledge distribution and management.

Al-Rubai'i \& Mohamad [2019] followed a critical approach to pinpoint the socio-psychological reflections of representation and identity in the negotiation of discourse between students and trainers in webinars. Social action in webinars suggests pro-power relations as means of academic discourse; trainers adopt intonation, discourse markers, and topic-shift to establish authority, while students adopt technology for participation. Al-Rubai'i and Mohamad found that language functions as a social identifier of relations in webinars and they state that more research is needed in the technology-discourse field, especially concerning language and conversation management in online courses.

AlQbailat [2019] found that conversations in online and offline environments are worth analyzing, and by comparing EFL students' online and face-to-face conversations, the author concluded that interaction in language learning situations can be beneficial for interaction analysts.

The role of webinars from teachers' perspectives was investigated by Emre [2019]. She compared webinar efficiency and perception between two groups of teachers; webinar attendees and non-webinar attendees, to check how useful and reliable webinars are for teachers and language teaching trainers, and how much performance teachers can achieve when using webinars. Emre found "having prior experience in the use of webinars affected teachers' perceptions. Older teachers and the teachers with more years of teaching experience were less competent and had less self-efficacy in the use of webinars [...] teachers should have more knowledge and resources to use webinars and may find ways to integrate them to teaching EFL and professional development." [Emre, 2019, p.74-75].

Gegenfurtner \& Ebner [2019] surveyed the practical trials related to webinars in higher education and professional settings through a randomized analysis of specific data. They found that webinars were effective in communicating professional and educational knowledge for receivers and that these online web-based trainings promoted information more than did physical or in-person workshops. Gegenfurtner \& Ebner's study recommended a further assessment and evaluation of online workshop implementation and delivery to test the reliability, practicality and applicability of the said workshops in learning-related aspects.

Adelakun \& Omolola [2020] analyzed e-learning use pragmatically in higher education in some developing countries. Their evaluation of the benefits and challenges associated with e-learning blamed underaverage Internet connection, outdated technology, shortage of trained personnel, lack of standard IT infrastructure, and absence of user-friendly learning platforms for the remarkable underimplementation of e-learning practices in developing countries. Adelakun \& Omolola, additionally, urged the adoption of the most modern technology in e-learning as a solution to implement it very well.

Charbonneau [2020] used a constructivist approach to investigate the presence and technology in the online Finnish education setting. His study indicated that social presence is impacted by certain behavioural determinants that often prevailed in the Finnish online learning practices. In a 
study based on observation, analysis, and investigation, Charbommeau demonstrated that there are academic norms, generally broader and more effective than educational technologies, that shape presence in online learning, citing shared group identity, collective presence, text-based online discussions as the key elements of such presence.

Drabkina \& Tanchuk [2020] studied discourse markers used in teaching and learning webinars, by analyzing selected English-learning and teaching webinars. Drabkina \& Tanchuk cited many exemplary levels of discourse markers in the said webinars; they referred to linguistic, pedagogical, technological features generated by online communication, for example, webinar presenters use anaphoric, cataphoric, and evidential devices. Drabkina \& Tanchuk reported that the presence of the said markers in pedagogical webinars is due to conversational peculiarities of online learning where listening and turn-taking proceed more differently than in face-to-face learning participations.

According to connectivism, knowledge is distributed across the web, and people's engagement with it constitutes learning [Kop, 2011].

As a result of the theoretical literature analysis, we may conclude that webinars are tools of modern technology, communication and interaction that are used in different spheres of our life and are aimed at creating successful communication and interaction between professionals of different scopes

\section{Context and Limit}

In this research, two key concerns are emphasized; academic webinars and knowledge. Academic webinars feature online presentations and discussions, where formal and academic discussions are held, along with the linguistic and conversational implications involved. Knowledge stands for what academic webinars are; presenters and listeners in such webinars exchange knowledge and new information concerning the topics discussed. Presenters deliver new information, share knowledge, and discuss updates over the topics discussed. Listeners, on the other hand, attend such webinars to gain new information and knowledge, and not only to get free or paid certificates. Knowledge can be communicated online to as many attendees as technology platforms allow, crossing all the linguistic, ethnic, geographical, spatio-temporal, and educational differences. An English-medium academically-oriented webinar streamed online by a presenter from Canada or South Africa can gain as many interested attendees as possible from other regions and territories across the globe regardless of the above-mentioned differences so long as the participants understand and communicate in English. Additionally, dialogue and interaction compose the most important elements of engagement whether in online or in face-to-face learning, where students, teachers, presenters, and audiences interact, chat, converse, and exchange information and other pieces of knowledge. Shi et al. [2004] have acknowledged the role of dialogue in online presentations of learning. They, accordingly, recommended a better understanding on how teachers can provide and facilitate engagement for students [Shi et al., 2004, p.749].

\section{Research Questions}

This research, aimed at exploring academic webinars, raises two questions:

1. How do the presenters in academic webinars communicate knowledge online?

2. What are the linguistic strategies, devices, and structures used in these webinars? 


\section{Corpus and Methodology}

The sample chosen for analysis involves an academic English-medium webinar delivered by English native-speakers in 2020. This webinar was chosen randomly as exemplary for academic webinars. Academic webinars cover various academic themes ranging from teaching to learning. The webinar selected is one hour and a half in length. The webinar was firstly downloaded, transcribed, and then annotated for analysis. Related appendixes are added at the end of the research. The source of this webinar is American English Webinars, from the YouTube channel AE Live webinars.

https://www.youtube.com/channel/UCBQ58amRJh3anfDtob6sBSQ

American English Webinars are free-to-attend, virtual, synchronous workshops set for English learning and teaching and mainly concentrate on the techniques, strategies, approaches, trends, methodologies, and practices used. These webinars aim to develop, update, and enhance the practices, ways, and methods of English learning and teaching. The webinars are endorsed by regional English language offices affiliated with the United States embassies and consulates across the world.

As for the analytical approach followed here, it is conversational analysis, which is an approach designed to study social interaction, embracing both verbal and non-verbal conduct, in situations of everyday life. The model chosen is that of Traum \& Hinkelman [1992], known as Conversation Acts. Traum \& Hinkelman's approach principally drew on previous approaches of conversational analysis. This approach consists of the following sub-acts:

1. Core speech acts: inform, request, and promise

2. Argumentation acts: elaborate, summarize, clarify, convince

3. Grounding acts: continue, acknowledge, repair, cancel

4. Turn-taking acts: keep, release, take

\section{Tool and Procedure}

The webinar video has been transcribed using the computer software OTTER 2.O Pro® (https://otter.ai/). The conversations in the webinar were annotated, that is, they were marked by speech symbols, following the notation of conversational conventions proposed by Gail Jefferson [2004]. The procedures for administering the sample are:

1. Selecting webinars

2. Transcribing webinars

3. Annotating webinars

4. Analyzing webinars

\section{Analysis}

For convenience, the webinar sampled is analysed in terms of duration. Time is taken into account in the analysis because it shows the duration of the turns and the times taken by moderators and presenters. Table (1) illustrates the webinar randomized for analysis as to duration, the number of moderators, and the number of presenters. 
Table (1) Webinar data

\begin{tabular}{|c|c|c|}
\hline No. of moderators & No. of presenters & Duration* \\
\hline 1 & 1 & $1: 00: 30$ \\
\hline
\end{tabular}

*hour, minute, second

\section{Webinar Data}

AE Live 9.5 - Superpowering your Lecture: Activities to Engage Learners and Gather Feedback

https://www.youtube.com/watch?v=8j7sObM41-w

Streamed online on November 18, 2020

Table (2) Webinar statistics

\begin{tabular}{|c|c|c|c|}
\hline Duration & Moderator's contribution & Presenter's contribution & Total \\
\hline Time(hr/m/s) & $00: 39: 09$ & $00: 21: 21$ & $1: 00: 30$ \\
\hline Turns taken & 18 & 17 & 35 \\
\hline Frequency & $68 \%$ & $32 \%$ & $100 \%$ \\
\hline
\end{tabular}

The statistics of Webinar (1) are demonstrated in Table (2) above, and they show that the moderator $(\mathrm{M})$ controlled the webinar more often than the presenter $(\mathrm{P})$. The moderator's time lasted for 39 minutes, while the presenter's time lasted only for 21 minutes. However, both the moderator and the presenter took almost similar number of turns; 18 turns were taken by the moderator, and 17 turns by the presenter. In percentile terms, the moderator's control is $68 \%$, whereas the presenter's is $32 \%$.

\section{Excerpts}

1. $\mathrm{P} \rightarrow$ What were you doing before the webinar paused?

2. $\mathrm{M} \rightarrow \mathrm{hhh} \rightarrow$ ok (.) So, what do you think everybody? we hope you are nice and honest (.) What were you doing before the webinar paused? (( )) let's see. We have D. (( )) We have C (( )) We have B. even if you choose A or D hhh you are here

3 . P $\rightarrow[[$ Yeh. ] thanks everybody. (( )) I really 000. So, what did you feel when taking this quiz?

4. M $\rightarrow$ ] ] Yeah (( )) so how do you feel when you take this quiz? (( )) how do you answer this question? (( )) does it ma::ke you feel certa::in w a a y? do you ha::ve any reactions to it? Let'::s see $(())$

5. M $\rightarrow$ Alfredo says he felt nervous (( )) Saeed said he felt more engaged (.2)

6. $\mathrm{M} \rightarrow$ Rosa said sh::e (( )) was listening to the speaker

7. $\mathrm{P} \rightarrow$ Yea::h $(())$ when you do this (.2) what are some challenges or concerns in your context you want to address?

8. $\mathrm{M} \rightarrow$ Ye::ah (.2) what are the challenges you want to::o (( )) ? Can you (.2) ah share some examples $(())$ of the challenges or concerns in your class? 


\section{Structure}

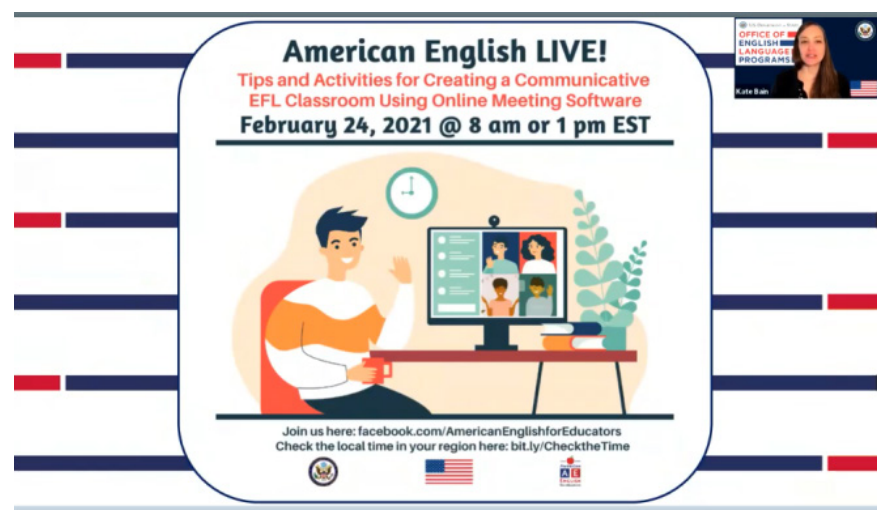

Fig. (1) moderator shares topmost-right side to introduce a webinar

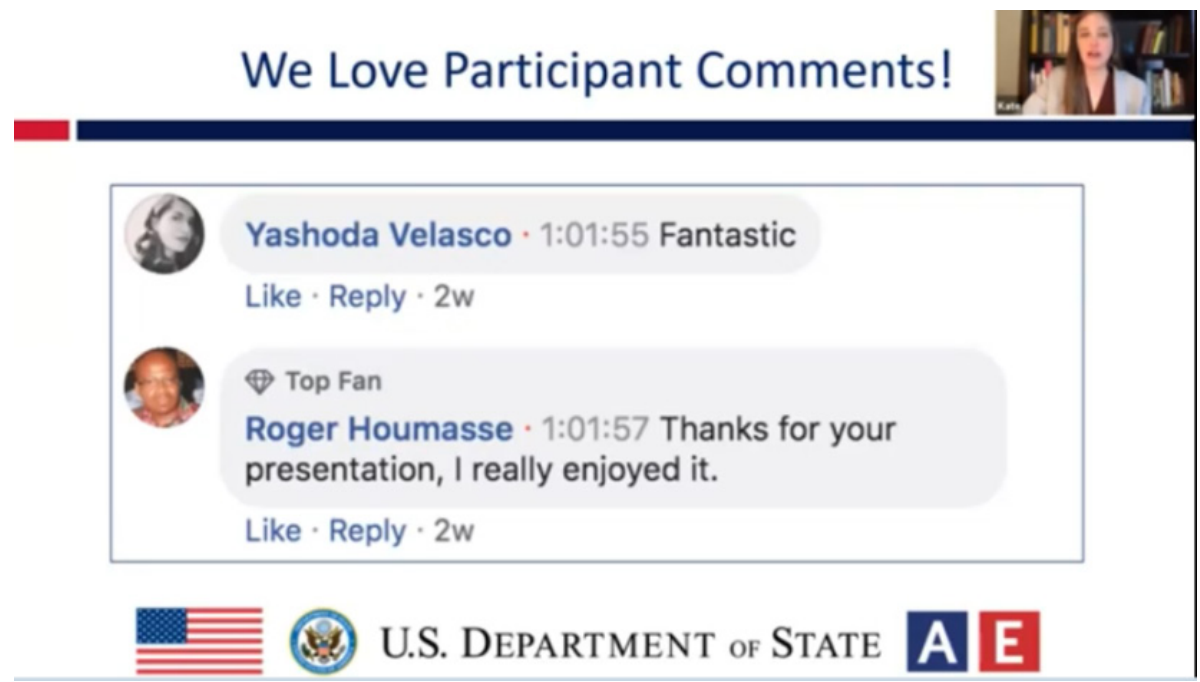

Fig. (2) moderator sharing top-screen to preview audience comments

This figure features a moderator introducing a webinar by sharing a top-screen right-hand direction. Technically, top-screen presentation is chosen because it is quite visible for all attendees, including moderators and the audience. Here, moderators introduce webinars by sharing on-screen content (consists of general introduction, topic familiarization, highlight on presenter's knowledgeability, and warming up webinar for the presenter to take the floor). The introductory content first shared on-screen by moderators consists of short texts. The sentences are generic, clear, and topic-focused. The texts may also contain brief bios about presenters; name, rank, achievements, and the like. Most moderators' pre-webinar introductions take 1 minute to 2 minutes and a half. Time and space issues are very critical in academic webinars. J. Heritage [2020] stated that "In webinars, moderators often have the advantage of information that is inaccessible to others, and this can create an obligation to "narrate" the visual content of their screens to justify moderating decisions that may be unique to the world of webinars." [Heritage, 2020, p.1]. 


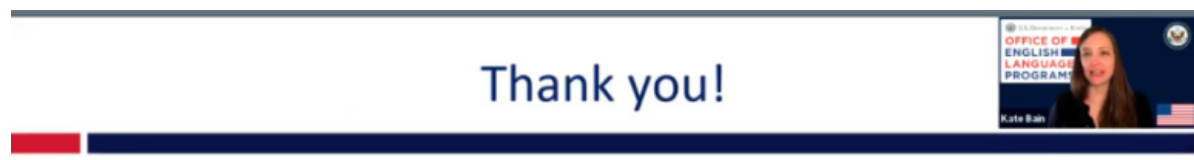

Email: americanenglishwebinars@fhi360.org

AE Live - Ning Community of Practice: americanenglishwebinars.com AE for Educators Facebook page: facebook.com/AmericanEnglishforEducators

AE website: americanenglish.state.gov

AE YouTube channel: youtube.com/StateAmericanEnglish

AE Facebook page: facebook.com/AmericanEnglishatState

\section{A a American English}

Fig. (3) Moderator sharing top-right hand corner screen to take audience questions

The figure above shows a full-screen explanation with the webinar presenter appearing on the right-top corner. In most webinars, presenters share interactive screens where the content is communicated to the audience through a live, synchronous, and audio-visual mode. The presenters are visible, audible, and interactive; they can be seen and heard by everybody watching or attending the webinar. In this token, the technology used plays a highly significant role; the more advanced the technology used in streaming the webinar, the more fruitful the webinar will be. Technology assistantship involves voice quality, high definition visibility, and non-interruption Internet service. The cross-screen presentation features a presenter, interactive content (mobile text-and image or pre-formatted slides), and a behind-the-screen moderator. The moderator's role is to introduce the webinar, familiarize the audience with the content and the presenter's knowledge, take audience questions, and close the webinar. Moderators sometimes interrupt presenters when necessary, for instance, when blackout is experienced, when presenters take over time, or in case of any technical failure. The content shared may not contain videos. Video sharing is not recommended in webinars as they are time-consuming and they require super-speed Internet, which may not be available to all attendees.

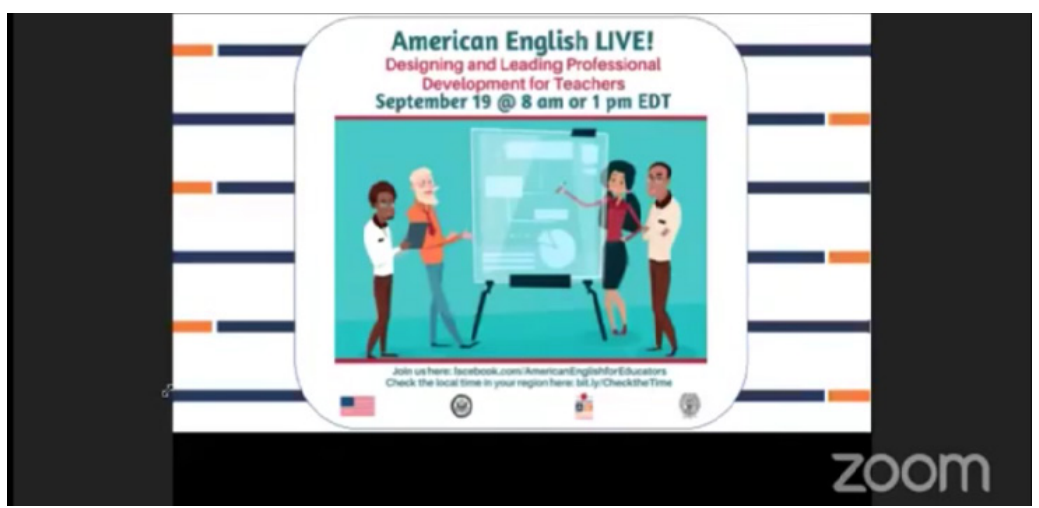

Fig. (4) Moderator's invisibility

The above figure demonstrates moderator invisibility. Nothing is visible in this webinar except the moderator's name with her voice audible while introducing a webinar. Moderators may choose to be invisible where they are only heard and are not seen on the screen in the webinar. In such cas- 
es, moderators introduce the webinar, familiarize the audience with the presenters, take audience questions, and close the webinars without appearing on screen.

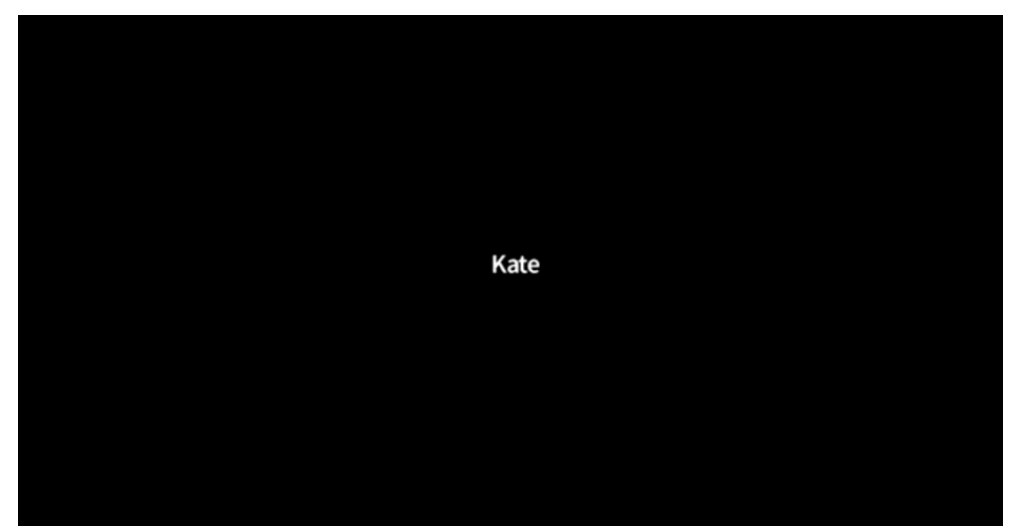

Fig. (5) Presenter's invisibility

Like any average webinar, academic webinars are based on a single-role flooring. That is, they linguistically proceed with the greater flooring or interaction role taken by presenters. Presenters, being the only speaker and interactant, control conversational participation by taking most of the time assigned to participants, hold the floor almost as long as the webinars, in addition to other tasks and strategies. That is why webinars in general are much closer to monoversations than they are to ordinary or systematic conversations. A moderator may introduce a webinar, allow the presenter to proceed, interrupt the presenter, and take audience questions. A presenter, on the other hand, can at any time interrupt the moderator and audience, close the webinar, and directly interact with the audience. Presenters, additionally, control webinars both linguistically and professionally. They control webinars linguistically by taking the single-one time participation, along with interruptions. Webinar presenters, also, control webinars professionally because they are more experienced and knowledgeable in the subjects discussed than moderators and audience. A two-hour (120-minute length) webinar is, in fact, one hour and a half for a presenter and 15 to 20 minutes for moderators and audience. Eventually, audience time is 5 to 10 minutes where they are allowed either to chat or directly ask moderators.

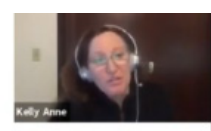

Tips and Activities for Creating a Communicative EFL Classroom Using Online Meeting Software

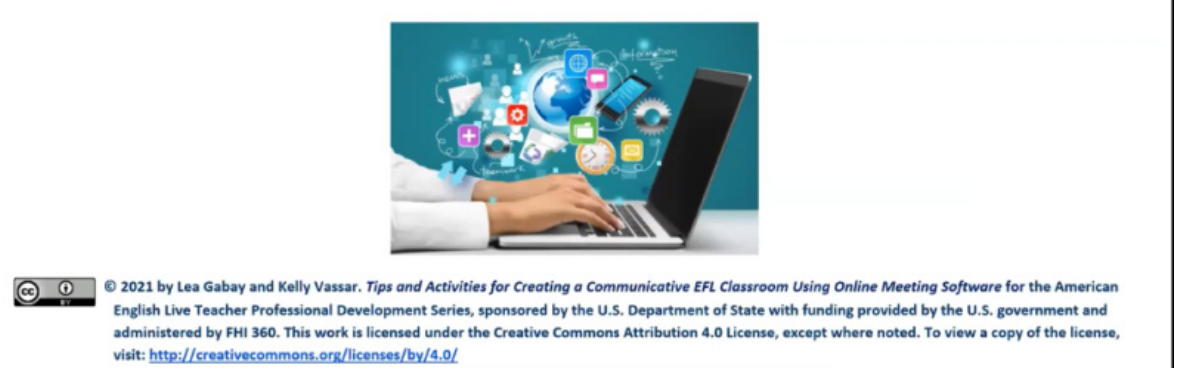

Fig. (6) presenter shares topmost-right side to introduce a webinar 
In the webinar closing, the moderator interrupts the presenter; ends the webinar, and takes audience comments or questions. Moderators' closing-ups often take 1 to 2 minutes to cover important or key points and issues. The audience, when allowed to ask questions, are either given on-screen chat (where they directly write questions in the dialogue box designated for this), or they submit their questions directly to the moderator. However, not all audience questions are answered or addressed, because moderators have only a short or limited time for questions. The moderator, then, reports the audience questions by paraphrasing or re-formulating them. Hence, for example, if an audience question goes like;

How can I verify if the journal to which I submit my manuscript is indexed in global publication databases?

The moderator will cut short this as;

How and where can we check indexed journals?

Reformulation and paraphrasing strategies, as occasionally adopted by webinar moderators, are done for conversational and discourse purposes. Apart from shortening lengthy sentences or questions for time and space issues, a moderator may re-formulate and paraphrase a question to accommodate the presenters' level. A presenter, due to various reasons, may not comprehend an audience question as moderators do. A webinar presenter is an expert in the field. Furthermore, in webinars with a multi-lingual audience (coming from various ethno-geographical and linguistic backgrounds and regions), moderators may act as interpreters by, for example, translating questions posed by non-native or other language speakers.

Based on the previous discussion, webinars can be re-defined as follows:

1. They are direct, online, synchronous seminars that are streamed live, and are delivered by professionals, facilitated by moderators, and attended by the audience.

2. Webinars are set for specific topics, fields, or functions wherein they are discussed and debated.

3. They are assisted by technology and are channeled by an audio-visual graphic interaction, where participants can contribute by speaking, listening, watching, displaying, and/or writing/ chatting.

4. Engagement in webinars is achieved by participation, and the desire to contribute. Even a single member of the audience attending the webinar can share views or opinions or can pose questions in the chat-box. Interruption, on the other hand, is possible in webinars through questions, screen-sharing, or silent showing.

5. The verbal part in webinars is solely held by moderators and presenters. As for the audience, they are allowed graphic interaction (they listen and chat or comment). This means that moderators and presenters converse with each other, while the audience listen and comment in the chat-box.

6. The tone in webinars is often formal and topic-specific.

7. Timelines, places, and languages are neutralized in webinars in favour of technology and the English language. The audience, being from various regions and territories in the world, stick to the online platform selected, attend the webinar at the time and date set, and communicate in English with the presenters and moderators.

8. The structure of webinars proceeds through three key phases: introduction (welcoming, warming up, familiarizing the participants with the topic and the presenter), engagement (passing conversational turns to presenters, turn-switch between moderators and presenters), and closing (replying to audience questions, thanking the presenters, and ending the webinar). 
9. Presenters in the webinars are expected to be professionals in their field, and thereby be able to discuss, elaborate on, explain, exemplify, comment, and reply to questions posed by moderators or by the audience.

\section{Conclusions}

1. Webinars are very important in helping professionals, trainers, and teachers of any major, profession, or field, to spread, exchange, and share knowledge. Given the nature of webinars, as they are almost completely spoken in the form and are streamed online, the participants engaged in webinars can benefit a lot.

2. The main features characteristic of webinars, especially on-screen display of visuals, slides, and written materials, and direct audio-verbal interaction, make such online workshops interesting and highly attended.

3. Interruption in webinars is achieved by humor, raising questions, answering questions, display of on-screen materials, and silent showing on the screen.

4. Turns in webinars may be exchanged or taken by passing, that is, the current speaker expressly says 'I am going to pass it over to my colleague/friend/...etc. (name). In other words, he/ she passes the turn to the next speaker, as when, for example, the moderator passes the floor/turn to the presenter.

5. Interaction in webinars is not restricted by traditional norms of exchange and conversation. Thanks to technology, the participants engaged in online environments of learning can proceed without being hindered by turn-taking, lack of time, or waiting. Technology in online learning has facilitated the strategies of conversation and enabled more communication.

\section{Discussion of Analysis}

1. Regarding the first research question (How do the presenters in academic webinars communicate knowledge online?), the analysis shows that presenters do so by using English as a common language of interaction and communication, by displaying on-screen slides, visuals, graphics, and various materials, by asking questions, by responding to audience questions and comments, and by spreading their professional knowledge.

2. As for the second research question (What are the linguistic strategies, devices, and structures used in these webinars?), the analysis shows that the most common strategies in webinars are reformulation, reposing questions, humour, silent appearance, yes-based agreement, asking questions, and interruption.

3. In the interactional and conversational structure of webinars, the moderator in the sampled webinar has almost the same time that is owned by the presenter. In other words, the moderator has contributed 18 times, whilst the presenter contributed 17 times, even though the moderator's takes last for short periods of time and are merely replies to questions or quick interruptions.

4. In the realization of the analytical approach in the webinar, the sub-acts most used in the webinar are core speech acts (inform, request), argumentation acts (elaborate, summarize, clarify), grounding acts (continue, repair, cancel), and turn-taking acts (keep, release, take).

5. In the webinar, the moderator receives turns by; great/ yeah/ yes/ ok/ wonderful, and submits turns by; thanks and great. On the other hand, the presenter receives the turns by yes. 
Table (3) Conversational Moves

\begin{tabular}{|c|c|c|c|}
\hline Move & Moderator & Presenter & Total \\
\hline Interruption & 0 & 2 & 2 \\
\hline Turn-taking & 18 & 17 & 35 \\
\hline Overlap & 1 & 3 & 4 \\
\hline Repair & 0 & 2 & 2 \\
\hline Humour & 8 & 1 & 9 \\
\hline Pause & 2 & 3 & 5 \\
\hline
\end{tabular}

Table (4) Analytical sub-acts

\begin{tabular}{|c|c|c|c|}
\hline Sub-act & Moderator & Presenter & Total \\
\hline Inform & 1 & 2 & 3 \\
\hline Request & 2 & 2 & 4 \\
\hline Elaborate & 1 & 4 & 5 \\
\hline Summarize & 2 & 3 & 5 \\
\hline Clarify & 1 & 2 & 4 \\
\hline Continue & 3 & 1 & 7 \\
\hline Acknowledge & 3 & 4 & 5 \\
\hline Repair & 1 & 4 & 1 \\
\hline Cancel & 1 & 0 & 4 \\
\hline Keep & 2 & 2 & 8 \\
\hline Release & 3 & 5 & 5 \\
\hline Take & 2 & 3 & 3 \\
\hline
\end{tabular}

\section{Future Areas of Research}

1. Arabic-medium webinars can be compared with English-medium webinars to find any similarities and differences, be they linguistic or non-linguistic.

2. Academic webinars can also be investigated pragmatically, for instance, in terms of the speech acts used, and the invisible meanings implicated.

3. Politeness is still a neglected and under-researched area in online discourse, especially in synchronous and live interactions. Hence, further studies are urged in this field.

4. Online discourse remains a fresh area especially for discourse analysts, with many other unsearched themes and issues.

5. Webinars in general can also be researched through multimodality to highlight the visuals, scripts, and graphics used in interaction and how they contribute to the presentation of webinars.

\section{Conflict of Interests}

The author of this paper declares no conflict of interests neither in the design of this research nor in the items, data, or techniques contained, used, or discussed therein.

\section{Acknowledgments}

The author wishes to thank all the anonymous persons/parties who have contributed to this research.

\section{Funding}

No specific financial grant or funding has been received in the authorship or publication of this paper from any commercial, private, public, or government party or agency. 


\section{REFERENCES}

1. Adelakun, N. \& Omolola, S. (2020). A pragmatic study on E-learning for higher education in developing countries. Proceedings of the $1^{\text {st }}$ National Conference, Nigerian Society of Engineers, Ilaro, Nigeria, 2-3 Nov., pp.14-20.

2. Agnes, W. S. (2012). Relationship between participation in the webinar \& students' behaviours \& engagement in online learning. Master Thesis, University of Toronto.

3 AlQbailat, N.M.I. (2019). Internet linguistics: A conversational analysis of online synchronous chat \& face-to-face conversations of EFL undergraduate students in Jordan. PhD Dissertation, Universidad Carlos III de Madrid, Spain.

4. Al-Rubai'i, A.M.H., \& Mohamad, M.S. (2019). A critical discourse analysis of the language of webinars: Politics building task. Journal of University of Duhok, 22.2, 349-364.

5. Başaran, B.Ç. (2014). Webinars as instructional tools in English language teaching context. Master Thesis, Middle East Technical University, Turkey.

6. American English Webinars (2020). YouTube AE Live webinars. Retrieved from https://www. youtube.com/channel/UCBQ58amRJh3anfDtob6sBSQ (accessed: 15 September, 2020)

7. Charbonneau, I. (2020). Social presence \& educational technologies in an online distance course in Finnish higher education: A social constructivist approach. Master Thesis, Stockholm University.

8. Clay, C. (2012). Great webinars: How to create interactive learning that is captivating \& fun. California: Pfeiffer.

9. Doherty-Sneedon, G., Anderson, A., O’Malley, C., Langton, S., Garrod, S., \& Bruce, V. (1997). Face-to-face \& video mediated communication: A comparison of dialog structure \& task performance. Journal of Experimental Psychology: Applied, 3 (2), 105-125.

10. Drabkina, I.V. \& Tanchuk, A.S. (2020). Discursive markers of webinars on teaching/learning English. European Proceedings of Social \& Behavioural Sciences, 105-117.

11. Emre, S. (2019). Webinars for teaching English as a foreign language \& for professional development: Teacher perceptions. Master Thesis, İhsan Doğramaci Bilkent University, Turkey.

12. Fetisova, S., Podkamennaya, E., \& Nevolina, K. (2018). Developing professional foreign language skills through webinars as online tool. SHS Web of Conferences, 50, 1-6.

13. Gee, J., \& Green, J. (1998). Discourse analysis, learning \& social practice: A methodological study. Review of Research in Education, 23, 119-169.

14. Gegenfurtner, A., \& Ebner, C. (2019). Webinars in higher education \& professional training: A meta-analysis \& systematic review of randomized controlled trials. Educational Research Review, 28, 3-19.

15. Heritage, J. (2020). Foreword. In Waring, H. \& Reddington, E. (eds.). Communicating with the public: Conversation analytic studies. London: Bloombsbury Academic, pp.1-6.

16. Ho, C.H., \& Swan, K. (2007). Evaluating online conversation in an asynchronous learning environment: An application of Grice cooperative principle. Internet \& Higher Education, 10:1, 3-14.

17. Hoeldtke, K., \& Raake, A. (2011). Conversation analysis of multi-party conferencing \& its relation to perceived quality. IEEE ICC 2011-International Conference on Communications, Kyoto, Japan, 5-9 June, 2011.

18. Jefferson, G. (2004). Glossary of transcript symbols with an introduction. In G.H. Lerner. (Ed.). Conversation analysis: Studies from the first generation. Amsterdam: John Benjamins Publishing, pp.13-31.

19. Jonassen, D., \& Remides, H. (2005). Mapping alternative discourse structures onto computer conferences. International Journal of Knowledge \& Learning, 1:1/2, 113-129. 
20. King, A.H. (2018). Doing being the moderator: Use of "respondent selection" during webinar Q\&As. Teachers College, 18 (1), 23-30.

21. Kop, R. (2011). The challenges to connectivist learning on open online networks: Learning experiences during a massive open online course. The International Review of Research in Open \& Distance Learning, 12(3), 19-38.

22. Mihai, A. (2014). The virtual classroom: Teaching European studies through webinars. European Political Science, 13, 4-11.

23. Mohorovicic, S., Lasic-Lazic, J., \& Strcic, V. (2011). Webinars in higher education. 2011 Proceedings of the 34th International Convention MIPRO, 23-27 May, 2011, Opatija, Croatia, 1271-1274.

24. Moore,C., Fisher, T.,\& Baber, E. (2016). Virtually unknown: Teacher engagement in an online conference. ELT Journal, 70 (2), 200-211.

25. Newman, B. (2013). Best practices for training webinars. Westchester County Business Journal, 9(31).

26. Reneland-Forsman, L., \& Magnusson, M. (2019). Supporting scholarly thinking in a Nordic teacher education webinar practice. Journal of University Teaching \& Learning Practice, 16:2, $1-14$

27. Ruiz-Madrid, N., \& Fortanet-Gómez, I. (2017). An analysis of multimodal interaction in a webinar: Defining the genre. In C.Vargas-Sierra. (ed.). EpiC series in language \& linguistics. Vol.2, 274-282.

28. Shi, S., Mishra, P., \& Bonk, C.J. (2004). Linkage between instructor moderation \& student engagement in synchronous computer conferences. Association of Education Communication \& Technology (AECT) International Convention, Chicago, Illinois.

29. Stein, G., Shibata, A., Bautista, M., \& Tokuda, Y. (2010). Webinar: An initial experience with webbased real time interactive clinical seminars for Japanese medical students. General Medicine, 11(2), 87-90.

30. Stoytcheva, M. (2018). Students' perceptions of online collaboration in a distance learning French language course. AIP Conference Proceedings 2048, 8-13 June, Sozopol, Bulgaria, 020030.

31. Sutton, L.M. (2012). Factors affecting quality discourse \& knowledge construction in an online university course. PhD Dissertation, North-central University, Arizona, USA.

32. Tan, S.-C., \& Tan, A.-L.(2006).Conversational analysis as an analytical tool for face-to-face \& online conversations. Educational Media International, 43(4), 347-361.

33. Traum, D.R., \& Hinkelman, E. (1992). Conversation acts in task-oriented spoken dialogue. Computational Intelligence, 8(3), 575-599.

34. Wang, S.K., \& Hsu, H.Y. (2008). Use of the webinar tool (Elluminate) to support training: The effects of webinar-learning implementation from student-trainers' perspective. Journal of Interactive Online Learning, 7 (3), 175-194.

35. Warren, A.N. (2018). Navigating assigned roles for asynchronous online discussions: Examining participants orientation using conversation analysis. Online Learning, 22 (4), 27-45.

36. Webinar. 2021. In Merriam-Webster.com. Retrieved from https://www.merriam-webster.com/dictionary/webinar (accessed: 15 January, 2021).

37. Wen, W., Yang, D., \& Rose, C.P. (2014). Linguistic reflections of student engagement in Massive Open Online Courses. The $8^{\text {th }}$ International AAAI Conference on Weblogs \& Social Media, June 1-4, 2014, California, USA, pp.525-534. 


\section{Appendix}

List of transcript symbols (following Jefferson (2004)

\begin{tabular}{|c|c|}
\hline Symbol & Meaning \\
\hline[ & Overlap onset \\
\hline$]$ & Overlap termination \\
\hline$\rightarrow$ & Speaker onset \\
\hline Speech & Emphasis \\
\hline$=$ & Turn continuation \\
\hline$()$. & Pause or interval \\
\hline$(.3)$ & Time gap \\
\hline$(())$ & Simultaneous taking \\
\hline$[[$ & Speakers' overlap \\
\hline $\begin{array}{c}\text { Speaker speech } \\
\text { speech }\end{array}$ & Latching or end of turn and continuation \\
\hline $\begin{array}{c}\text { Speaker }= \\
\text { Speaker }\end{array}$ & Sound or word stretch \\
\hline Spe::ech & Humor or laugh \\
\hline hhh & Sigh \\
\hline $\mathbf{0 0 0}$ &
\end{tabular}

\section{About the author:}

Mohammed Nasser Abdulsada is assistant professor of English at Wasit University, Iraq, where he teaches English, linguistics, and ESP to Bachelor students. He also teaches and supervises Master students. 